\title{
Chapter 18 \\ The Influence of Earthquake Magnitude on Hazard Related to Induced Seismicity
}

\author{
Benjamin Edwards
}

\begin{abstract}
An increased focus on seismic hazard related to induced seismicity means that state-of-the-art approaches for earthquake monitoring and hazard estimation associated to tectonic earthquakes are now being applied at smaller and smaller scales. This chapter focuses on a specific issue related to this shift of focus to relatively small earthquakes in close proximity to urban areas. In tectonic earthquake hazard analyses we typically rely on a simple power-law scaling relating earthquake magnitude and recurrence. It is known, however, that for smaller earthquakes, the scaling between different magnitude types is not necessarily linear - meaning that a power law cannot be maintained over all magnitude types. Extrapolation to estimate the recurrence of earthquakes not yet recorded at the study site is therefore non-trivial. For earthquake hazard, the moment magnitude is typically used as input as it is easy to relate to ground motion through empirical equations or simulation approaches. However, for earthquake monitoring, maintaining a complete catalogue including moment magnitude of small events is technically difficult. Instead, a point-measure based magnitude, such as the local magnitude is usually determined. In the following the impact of the non-linear scaling between the magnitude of choice for local monitoring - the local magnitude - and that used for hazard analysis - the moment magnitude - is explored.
\end{abstract}

\subsection{Introduction}

Ground shaking from induced seismicity associated with stimulation and exploitation of the near-surface, for example, related to geothermal reservoirs, shale oil or gas extraction and $\mathrm{CO}_{2}$ storage increases the risk exposure of the local population. For instance, an enhanced deep-geothermal project in Basel, Switzerland, triggered

\footnotetext{
B. Edwards $(\bowtie)$

Swiss Seismological Service, ETH Zürich, Switzerland

Department of Earth, Ocean and Ecological Sciences, University of Liverpool, UK e-mail: edwards@sed.ethz.ch
} 
an $\mathrm{M}_{\mathrm{L}} 3.4\left(\mathrm{M}_{\mathrm{w}} 3.2\right)$ earthquake at a depth of less than $5 \mathrm{~km}$ below the city (Baer et al. 2007). Along with thousands of aftershocks (Deichmann and Giardini 2009), the event led to insurance claims relating to non-structural damage (e.g., hairline cracks) of more than $\$ 7.5 \mathrm{M}$ with total costs of $\$ 9 \mathrm{M}$ (pers. Comm. Geo Explorers Ltd., 2012; Giardini 2009).

A growing body of evidence, while still inconclusive, suggests that seismicity related to injection induced earthquakes is increasing. For example, Ellsworth (2013) showed that "within the central and eastern United States, the earthquake count has increased dramatically over the past few years". This, in turn, means that "regions where the rate increased may be more hazardous than forecast by the 2008 version of the U.S. National Seismic Hazard Map" (Ellsworth 2013). Although direct causality between increasing seismicity and projects related to the exploitation of the shallow crust is not clear in all cases, what is important is that the potential for increased hazard related to induced seismicity (and consequently risk) should be assessed prior to, and during, such operations. Two primary components drive estimates of seismic hazard (and its uncertainty): seismicity rates and groundmotion prediction. In the following chapter, the issues surrounding the determination of seismicity rates are discussed with a focus on the influence of earthquake magnitude assessment, as routinely carried out during seismic monitoring.

Seismicity is typically modelled in probabilistic seismic hazard analyses (PSHAs) using the Gutenberg-Richter (1944, hereafter G-R) relation, with the cumulative number of events (with magnitude greater than $\mathrm{M}$ ), $\mathrm{N}$, given by:

$$
\begin{aligned}
\log _{10}(N) & =a-b M & & M \leq M_{\text {Max }} \\
N & =0 & & M>M_{M a x}
\end{aligned}
$$

with a maximum magnitude $M_{\text {Max }}$ (Smith 1976) defined by a probability density function. In practice the truncated exponential G-R relation is used (Cornell and Vanmarcke 1969). This relation is used to characterize faults or source zones based on observed seismicity in terms of overall activity rate $(a)$ and the proportion of large to small events (b) (e.g., Wiemer and Wyss 2002). While the $a$-value can be thought of as a measure of the overall seismicity, the $b$-value has been previously linked to factors such as changes in differential-stress, for example, due to: asperities (Wiemer and Wyss 1997), different faulting regimes (Schorlemmer et al. 2005) or due to source depth (Spada et al. 2013). $a$ - and $b$-values can be directly estimated for a given source zone or fault based on observed (and historical) seismicity above a time-dependent completeness threshold $M_{c}$. Maximumlikelihood approaches (Aki 1965; Utsu 1965; Bender 1983) are normally used to determine $a$ - and $b$-values, along with their confidence intervals. While based on simple observational statistics, the estimation of G-R parameters is subject to uncertainties due to determined magnitudes (Kijko 1985; Tinti and Mulargia 1985) and due to catalogue completeness (Lee and Brillinger 1979; Weichert 1980).

Given a source model, PSHAs estimate the probability of exceedance for a given ground-motion using a Ground Motion Prediction Equation (GMPE) (Cornell 1968). Moment magnitude $\left(M_{w}\right)$ is the magnitude of choice for seismic hazard 
based on tectonic seismicity: it does not saturate and is compatible with palaeoseismological and geological estimates of ancient earthquakes and maximum earthquake magnitude. This is because it is based on the seismic moment $\left(\mathrm{M}_{0}\right)$, of which the contributing factors are fault area and slip (assuming constant rigidity). In addition, and of importance to GMPEs developed for induced seismicity is the possibility to base time-series simulations directly on $\mathrm{M}_{\mathrm{w}}$. For instance, Douglas et al. (2013) presented GMPEs using 36 simulation models based on various source $\left(\mathrm{M}_{\mathrm{w}}\right.$, stress-drop), path (regional Q) and local site conditions (local attenuation $\kappa_{0}$ ). As a result of these advantages, GMPEs in the literature are predominantly developed using $\mathrm{M}_{\mathrm{w}}$ and I will use it as the 'reference' magnitude for this discussion.

Clearly, in order to maintain consistency in PSHA, magnitudes used in the source model and the GMPE should be the same. If a G-R based source model was developed using, for example, local magnitude (Richter 1935) - typically routinely determined at seismological observatories - then a magnitude conversion would be required between estimating the rate (based on $\mathrm{M}_{\mathrm{L}}$ ) and computing the associated ground-motion (based on $\mathrm{M}_{\mathrm{w}}$ ). In the ideal case, a G-R source model can be developed entirely using $\mathrm{M}_{\mathrm{w}}$ (i.e., for tectonic activity in seismically active areas). However, $\mathrm{M}_{\mathrm{w}}$ cannot always be calculated for small events due to ambient noise. Furthermore, depending on the frequency content analysed, estimation of $M_{w}$ for small events may introduce systematic bias due to high frequency effects such as site-amplification and attenuation (Stork et al. 2014). In order to obtain complete earthquake catalogues (critical for measuring the cumulative number of events in Eq. 18.1) local monitoring network operators therefore typically estimate magnitudes based on simple-to-measure parameters such as peak-amplitude $\left(\mathrm{M}_{\mathrm{L}}\right)$ or signal duration $\left(\mathrm{M}_{\mathrm{d}}\right)$. These catalogues are then supplemented with $\mathrm{M}_{\mathrm{w}}$ in the case that it is available (e.g., Fäh et al. 2011) and conversion equations (e.g., $M_{w}=f\left(M_{L}\right)$ ) are used to estimate $M_{w}$ of small events.

It is logical to reason that an earthquake has a single 'magnitude', and that while some scatter may be apparent, each measure $\left(\mathrm{M}_{\mathrm{w}}, \mathrm{M}_{\mathrm{d}}, \mathrm{M}_{\mathrm{L}} \ldots\right)$ should lead to the same broadly consistent value for properly calibrated scales. However, this is not the case: independent estimates of different earthquake properties can lead to systematic differences between different scales, particularly at extremes of magnitudes (either very small or very large) relative to where the initial magnitude scale calibration was made. For instance, Hanks and Boore (1984) showed that the observed curvature of $\mathrm{M}_{\mathrm{L}}$ versus $\mathrm{M}_{\mathrm{W}}$ data over an extended magnitude range of Californian earthquakes $\left(0 \leq \mathrm{M}_{\mathrm{L}} \leq 7\right)$ could be explained by a frequencydependent interaction of the earthquake source, attenuation and instrument response of the Wood-Anderson Seismometer. In this case, determination of a linear scaling between $M_{L}$ and $M_{w}$ would lead to a systematic underestimation of $M_{w}$ (Hanks and Boore 1984). Edwards et al. (2010) used the same simulation method to model and explain, in terms of source, path, site, and instrument-effects, the observed curvilinear scaling of Swiss earthquake magnitudes over a range $1.4 \leq \mathrm{M}_{\mathrm{L}} \leq 5.5$. Subsequently, Goertz-Allmann et al. (2011) developed a $\mathrm{M}_{\mathrm{L}}$ to $\mathrm{M}_{\mathrm{w}}$ scaling relation for Switzerland by collecting independent estimates of $\mathrm{M}_{\mathrm{w}}$ and $\mathrm{M}_{\mathrm{L}}$ over a range of $0.2 \leq \mathrm{M}_{\mathrm{L}} \leq 5.5$ and found similar scaling to a model developed based on a Europe- 
wide dataset (Grünthal et al. 2009). In the range $3 \leq \mathrm{M}_{\mathrm{L}} \leq 6$ the models tend to show that $\mathrm{M}_{\mathrm{w}} \approx \mathrm{M}_{\mathrm{L}}-0.3$. However, below $\mathrm{M}_{\mathrm{L}} 3$ the models deviate from 1:1 scaling systematically: with a decrease of 1 unit in $\mathrm{M}_{\mathrm{L}}$ corresponding to only a $\sim 0.6-0.7$ unit decrease in $\mathrm{M}_{\mathrm{w}}$.

There is no guarantee that different magnitudes scale 1:1. Indeed, such comparisons extend to many different magnitude scales (e.g., Bormann et al. 2009). Careful initial calibrations nevertheless ensure that over a broad region of interest, earthquake magnitudes using different scales are consistent. For instance, Choy and Boatwright (1995) defined the energy magnitude $\mathrm{M}_{\mathrm{E}}$ to be consistent to the surface wave magnitude $\left(\mathrm{M}_{\mathrm{S}}\right)$ in the range $5.5<\mathrm{Ms} \leq 8.2$. In the past, earthquakes of 'interest' have focussed on those easily recordable on national networks (e.g., $M \gtrsim 3$ ) or teleseismic networks (e.g., $M \gtrsim 5$ ). This then corresponds to where magnitude scales tend to be broadly consistent (i.e., $M \gtrsim 3-5)$. In terms of monitoring induced seismicity, and the estimation of seismic hazard based on these observations, we must therefore fully consider not only the influence of measured earthquake magnitude, but also the magnitude scale itself.

\subsection{Influence of $\mathrm{M}_{\mathrm{L}}$ on G-R $a$ - and $b$-Values}

In the following the focus is placed on $\mathrm{M}_{\mathrm{L}}$ as it is the most commonly routinely determined magnitude at seismological observatories or local monitoring networks. The computation of $\mathrm{M}_{\mathrm{L}}$ at small scale monitoring networks can be usually considered complete down to even $\mathrm{M}_{\mathrm{L}} \approx 1$ or even lower. For example, a small scale monitoring network (consisting of seven stations with inter-station spacing on the order of a few $\mathrm{km}$ ) related to a deep geothermal project in St. Gallen, Switzerland, had a magnitude of completeness $\mathrm{M}_{\mathrm{L}} \approx-1$. Catalogue completeness levels at such low magnitude levels was achieved by implementing cross-correlation techniques and single borehole-station magnitude determination (Edwards et al. 2015). While the $\mathrm{G}-\mathrm{R}$ relation was initially determined based on the analysis of $\mathrm{M}_{\mathrm{L}}$ data in California, common usage tends to make the assumption that it is $\mathbf{M}_{w}$ (and consequently $\log \left(\mathrm{M}_{0}\right)$ and its constituents: fault area and slip) that scales as a power law with the cumulative number of events. As an example of the impact of curvilinear scaling between $\mathrm{M}_{\mathrm{L}}$ and $\mathrm{M}_{\mathrm{w}}$ on seismic hazard estimation I therefore show in the following section its impact on Gutenberg-Richter (G-R) $a-$ and $b$ values using simulated earthquake catalogues.

\subsubsection{Simulation Method}

I generate a synthetic earthquake catalogue consisting of events with seven different moment magnitudes $\left(\mathrm{M}_{\mathrm{w}} 1-7\right)$, with each event recorded at seven locations $(10,20,30,50,70,100$ and $200 \mathrm{~km})$. The occurrence of events follows an arbitrary G-R relation with $a=3.0$ and $b=1.0$. For each recording a stochastic seismogram 
is generated (Hanks and Boore 1984; Boore 2003), which can in turn be used to determine $\mathrm{M}_{\mathrm{L}}$ of the event by measuring the peak amplitude on a synthesized Wood-Anderson Seismometer.

The synthetic stochastic seismograms are generated from a simple model of the Fourier acceleration spectrum (FAS), comprising of the far-field representation of the displacement source (Brune 1970, 1971):

$$
E(f)=\frac{M_{0} C}{R\left[1+\left(\frac{f}{f_{c}}\right)^{2}\right]}
$$

with $M_{0}$ the seismic moment (in SI units), and $C$ a constant which accounts for the free-surface, average radiation pattern, slip velocity and density. Geometrical spreading is accounted for using the hypocentral distance, $R$. The moment magnitude scale is defined by $M_{0}$ :

$$
\mathrm{M}_{\mathrm{w}}=\frac{2}{3} \log _{10} M_{0}-6.0 \dot{3}
$$

(Hanks and Kanamori 1979). Assuming a circular crack model (Eshelby 1957) the source corner-frequency $\left(f_{c}\right)$ can be calculated using:

$$
f_{c}=0.4906 \beta\left(\frac{\Delta \sigma}{M_{0}}\right)^{\frac{1}{3}}
$$

where $\Delta \sigma$ is the stress drop of the earthquake (SI units) and $\beta$ is the shear-wave velocity $(\beta=3,500 \mathrm{~m} / \mathrm{s})$. In order to account for anelastic attenuation along the source-receiver path an exponential decay function is used:

$$
B(f)=\mathrm{e}^{-\pi f \frac{R}{\beta Q}},
$$

(Knopoff 1964) with $Q$ the quality factor and $R$ the hypocentral distance (in $\mathrm{m}$ ). The full synthetic stochastic acceleration time-series can be calculated based on the FAS $(E(f) B(f))$ and a given duration model. For the duration model we adopt a simple model based on source magnitude and distance from the source:

$$
T=\frac{1}{f_{c}}+0.05 R
$$

(Herrmann 1985). The Local Magnitude is calculated using an adapted from of the original relation used by the Swiss Seismological Service:

$$
\begin{aligned}
& \mathrm{M}_{\mathrm{L}}=\log _{10} A+0.0180 R+1.87 \text { for } R \leq 60 \mathrm{~km} \\
& \mathrm{M}_{\mathrm{L}}=\log _{10} A+0.0038 R+2.72 \text { for } R>60 \mathrm{~km}
\end{aligned}
$$


with $R$ in $\mathrm{km}$ and $A$ the peak displacement (in $\mathrm{mm}$ ) of the ground-motion convolved with the response of a Wood-Anderson Seismograph. In practice, since $\mathrm{M}_{\mathrm{L}}$ is based on a peak measure $(A)$ of the Wood-Anderson seismogram with natural period $0.8 \mathrm{~s}$ and damping of 0.69, random-vibration theory [RVT, (Cartwright and LonguetHiggins 1956)] can be used to directly calculate $A$ using the duration model adapted to account for the Wood-Anderson oscillator response (Liu and Pezeshk 1999) and the FAS (Hanks and Boore 1984).

\subsection{Results: G-R $a$ - and $b$-Values from $M_{L}$}

Across the various simulation models with different source $\left(\Delta \sigma, \mathrm{M}_{\mathrm{w}}\right)$ and attenuation terms (Q) it is apparent, as expected, that the $a$ - and $b$-values obtained using $\mathrm{M}_{\mathrm{L}}$ are different from those obtained using $\mathrm{M}_{\mathrm{w}}$. This fact is of course, consistent with the fact that the $\mathrm{M}_{\mathrm{L}}$ to $\mathrm{M}_{\mathrm{w}}$ scaling relation is curvilinear. The exact difference is driven by the source properties $(\Delta \sigma)$, the attenuation $(\mathrm{Q})$, and the interaction of the earthquake spectrum and the Wood-Anderson Seismometer used to compute $M_{L}$. This was originally shown by Hanks and Boore (1984) to be the driving force behind the $\mathrm{M}_{\mathrm{L}}$ to $\mathrm{M}_{\mathrm{w}}$ scaling behaviour and therefore directly propagates into the $\mathrm{G}-\mathrm{R}$ relation. As a result of the curvilinear scaling, the magnitude range over which the G-R relation is calculated also has a significant impact on the differences found by using different magnitude scales.

\subsubsection{Influence of Stress-Drop}

The reference G-R relation using $\mathrm{M}_{\mathrm{w}}$ with $b=1.0$ is shown in Fig. 18.1 along with four simulated catalogues for which $\mathrm{M}_{\mathrm{L}}$ is used instead of $\mathrm{M}_{\mathrm{w}}$. In this case only geometrical (not anelastic) attenuation was applied. For each of the four catalogues a different stress drop is used: $0.1,1,5$ and $10 \mathrm{MPa}$. The resulting differences show the influence of the stress-drop on $\mathrm{M}_{\mathrm{L}}$ and consequently $a$ - and $b$-values. In Fig. 18.1a it can be immediately seen that the largest deviation from the G-R relation is apparent at higher magnitudes. This is due to the saturation of the $\mathrm{M}_{\mathrm{L}}$ scale: at some point, despite increasing the moment of the earthquake in equal steps, the increase in $\mathrm{M}_{\mathrm{L}}$ slows (and eventually stops). This is a well-known phenomenon typically considered to occur around M6-7, however, an interesting aspect to consider is that the point at which saturation begins is controlled by the stressdrop. For low values (e.g., $\Delta \sigma=0.1 \mathrm{MPa}$ to $1 \mathrm{MPa}$ ), even $\mathrm{M}_{\mathrm{L}}>4$ events show the beginning of saturation: an effect that artificially increases the b-value. As a general observation, systematically low stress-drop events tend to increase the apparent b-value when using $M_{L}$ in the high magnitude range. This effect should not be particularly problematic since we can observe a departure from the linear G-R law, and consequently limit the fitting range to below where the effect starts. 
Furthermore, for the larger events susceptible to saturation, it is likely that direct computations of $\mathrm{M}_{\mathrm{w}}$ will be available.

Avoiding the saturation effect, which is not particularly relevant for induced seismicity, and instead focusing on the lower magnitudes (Fig. 18.1b) we nevertheless still see a systematic variation of the b-value depending on the stress-drop used in the simulations. Generally (apart from the lowest stress-drop catalogue), the b-value is artificially decreased. For the $\Delta \sigma=10 \mathrm{MPa}$ catalogue, the b-value is
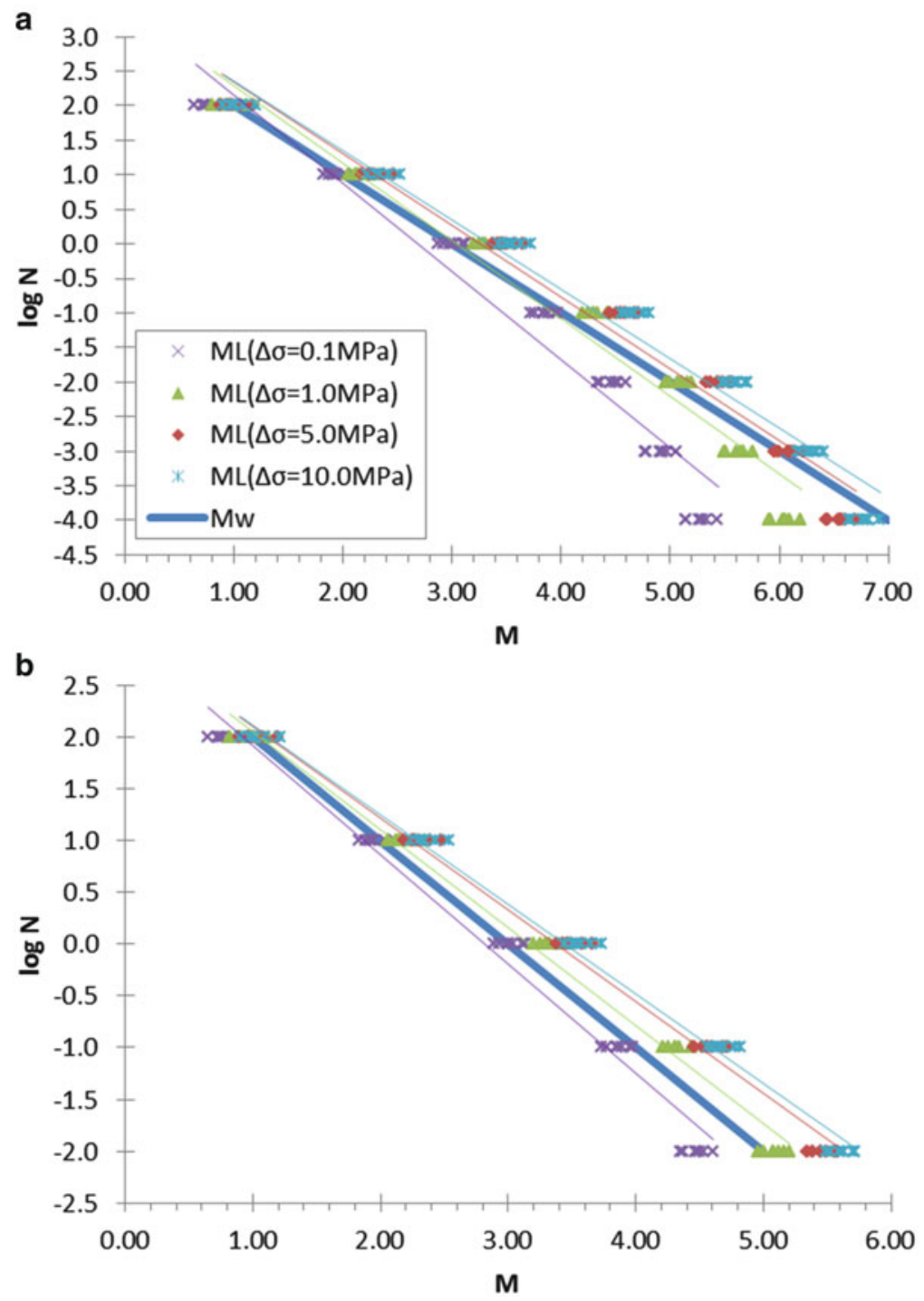

Fig. 18.1 G-R relation using Mw and ML for the synthetic catalogues. (a) For all events; (b) for events with $\mathrm{Mw} \leq 5$ 
0.86; for $\Delta \sigma=5 \mathrm{MPa}, \mathrm{b}=0.89$; for $\Delta \sigma=1 \mathrm{MPa}, \mathrm{b}=0.94$ and for $\Delta \sigma=0.1 \mathrm{MPa}$ $\mathrm{b}=1.05$. These values are computed over the range $1 \leq \mathrm{M}_{\mathrm{w}} \leq 5$, limiting the upper magnitude to 4 may slightly decrease the values further.

\subsubsection{Influence of Attenuation}

In the previous analysis the influence of the stress-drop was isolated by neglecting anelastic attenuation. However, in reality a complex interaction between the stressdrop, attenuation and the instrument response all play a role in the $\mathrm{M}_{\mathrm{L}}$ assigned to a particular event (Hanks and Boore 1984). A further reason that anelastic attenuation is important is apparent if we consider that the $\mathrm{M}_{\mathrm{L}}$ relation (Eq. 18.7) only accounts for frequency independent attenuation (i.e., the $+\alpha \mathrm{R}$ term).

Taking the catalogue with $\Delta \sigma=5 \mathrm{MPa}$ I now apply anelastic attenuation (Fig. 18.2). For $\mathrm{Q}=1,000$ the $\mathrm{b}$-value is further reduced from $b=0.89$ without attenuation to $b=0.82$, and using $\mathrm{Q}=500 \mathrm{I}$ obtain $b=0.79$. Such variations in the b-value seem quite strong, however, if we look only in the range $3 \leq \mathrm{M}_{\mathrm{w}} \leq 5$, where such statistics are often calculated (e.g., for seismic hazard), the smallest effect on the $b$-value is observed (Fig. 18.3). Interestingly, the $a$-value is increased in this example, consistent with the aforementioned difference between $\mathrm{M}_{\mathrm{w}}$ and $\mathrm{M}_{\mathrm{L}}$ of 0.3 in this range (Goertz-Allmann et al. 2011; Grünthal et al. 2009). As a result, if using magnitudes of interest for tectonic seismic hazard $\left(3 \leq \mathrm{M}_{\mathrm{w}} \leq 5\right)$, and applying a simple linear conversion (e.g., $\mathrm{M}_{\mathrm{w}}=\mathrm{M}_{\mathrm{L}}-0.3$ ), one would observe similar $a$ - and $b$-values to if one had been able to use $\mathrm{M}_{\mathrm{w}}$ directly. The effects discussed here may also be further pronounced if considering the influence of site-amplification on $\mathrm{M}_{\mathrm{L}}$ values. Whilst site amplification tends not to affect $\mathrm{M}_{\mathrm{w}}$ due to its long-period basis, $\mathrm{M}_{\mathrm{L}}$ is computed over a period range where it is common for strong amplification effects to be present.

\subsection{Regional Variability Between $M_{L}$ Values}

So far this chapter has focused on the impact of using $M_{L}$ in the standard G-R relation without accounting for the curvilinear scaling between $M_{w}$ and $M_{L}$. However, a major problem to address in the prediction of ground motion for induced seismicity is the significant variability of reported earthquake magnitude from agency to agency (Fäh et al. 2011). Edwards and Douglas (2014) homogeneously computed earthquake moment- and local-magnitude for events related to Enhanced Geothermal Systems (EGSs) in Basel (Switzerland), Soultz (France) and Cooper Basin (Australia); natural geothermal fields in Geysers (California) and Hengill (Iceland), and a gas-field in Roswinkel (Netherlands). As shown in previous studies, published catalogue $\left(\mathrm{M}_{\mathrm{L}}\right)$ magnitudes differed widely with respect to a common $\mathrm{M}_{\mathrm{L}}-\mathrm{M}_{\mathrm{w}}$ scaling relation, with up to a unit of magnitude difference. Using non-specific conversions from catalogue magnitudes (e.g., $M_{L}$ ) to $M_{w}$ for use in 

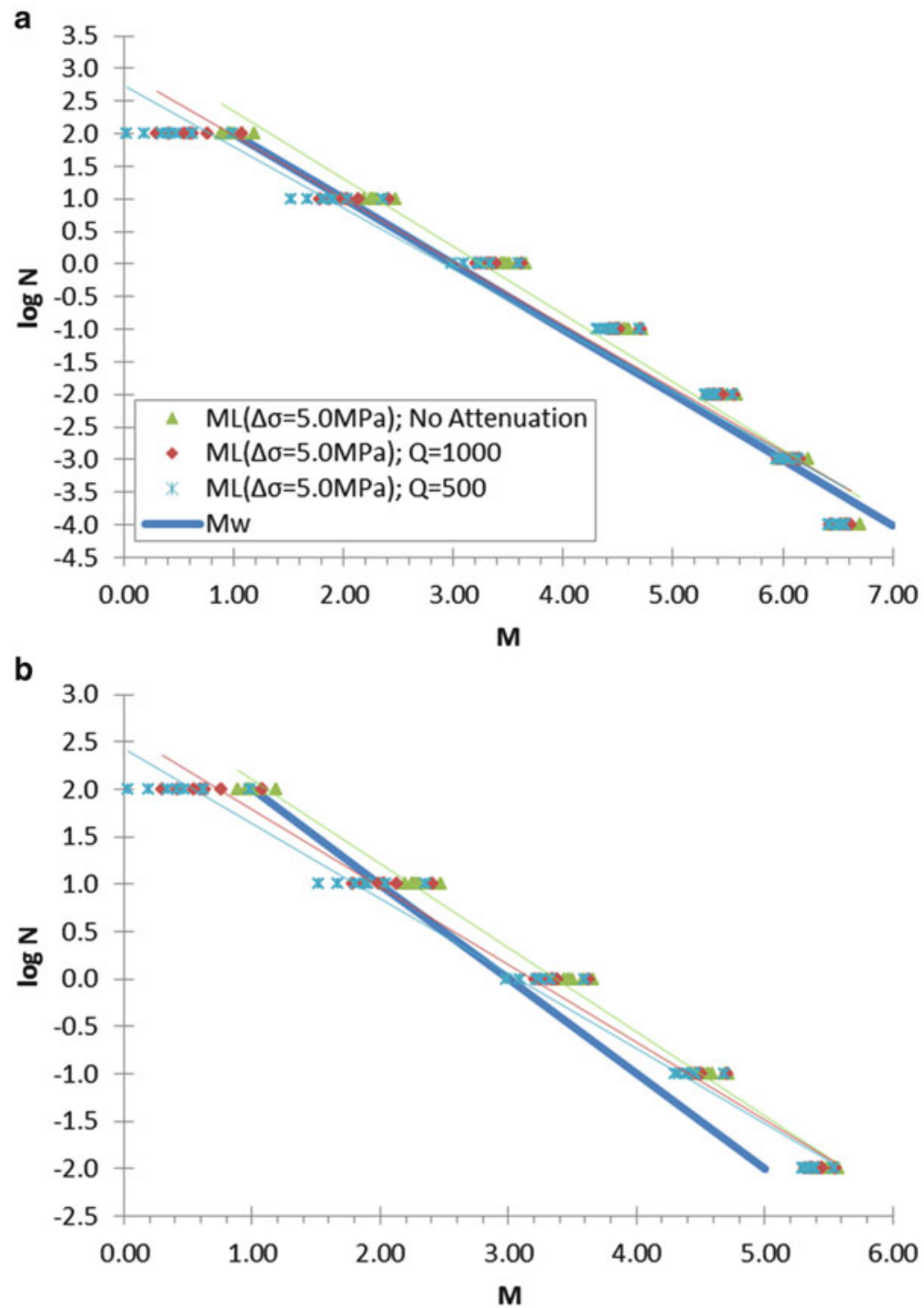

Fig. 18.2 G-R relation using $\mathrm{M}_{\mathrm{w}}$ and $\mathrm{M}_{\mathrm{L}}$ for synthetic catalogues using $\Delta \sigma=5 \mathrm{MPa}$ and different attenuation. (a) For all events; (b) for events with $\mathrm{M}_{\mathrm{w}} \leq 5$

GMPEs would subsequently lead to significant bias. On the other hand, Edwards and Douglas (2014) showed that given a common magnitude definition (and corresponding attenuation corrections), the scaling between moment- and localmagnitude of small induced earthquakes follows a second-order polynomial (Fig. 18.4) consistent with previous studies of natural seismicity (Goertz-Allmann et al. 2011; Grünthal et al. 2009). Using both the Southern-California $M_{L}$ scale and 


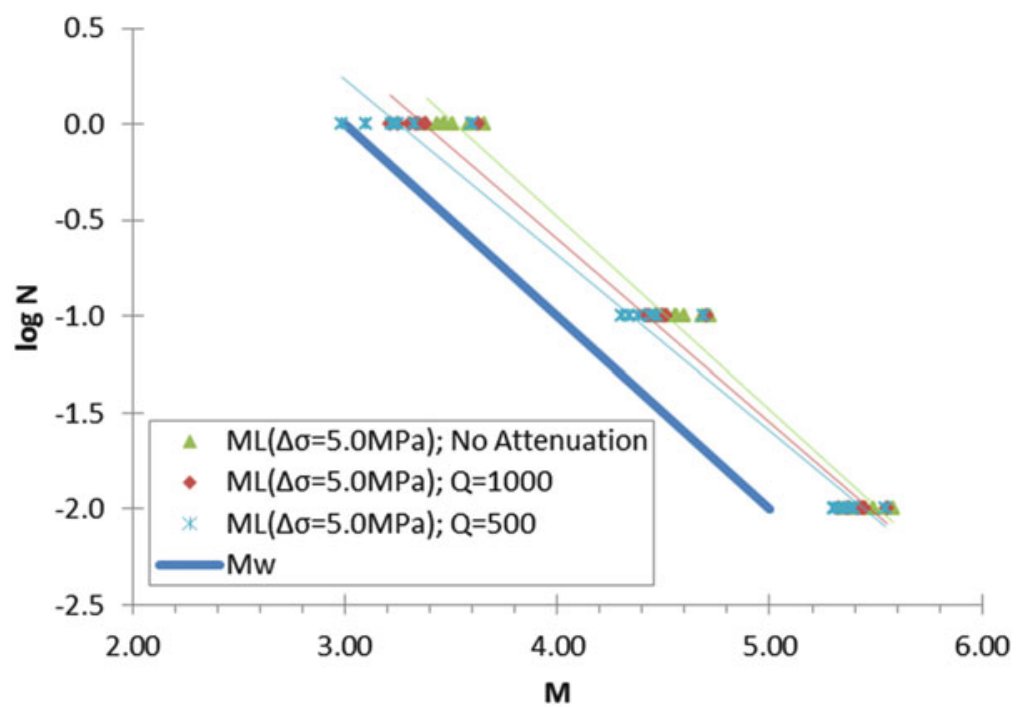

Fig. 18.3 G-R relation using $\mathrm{M}_{\mathrm{w}}$ and $\mathrm{M}_{\mathrm{L}}$ for synthetic catalogues using $\Delta \sigma=5 \mathrm{MPa}$ and different attenuation for events with $3 \leq \mathrm{M}_{\mathrm{w}} \leq 5$. Note that, for this magnitude range, after accounting for a generic linear conversion (e.g., $\mathrm{M}_{\mathrm{w}}=\mathrm{M}_{\mathrm{L}}-0.3$ ), one would obtain similar a- and b-values to those for $\mathrm{M}_{\mathrm{w}}$

a

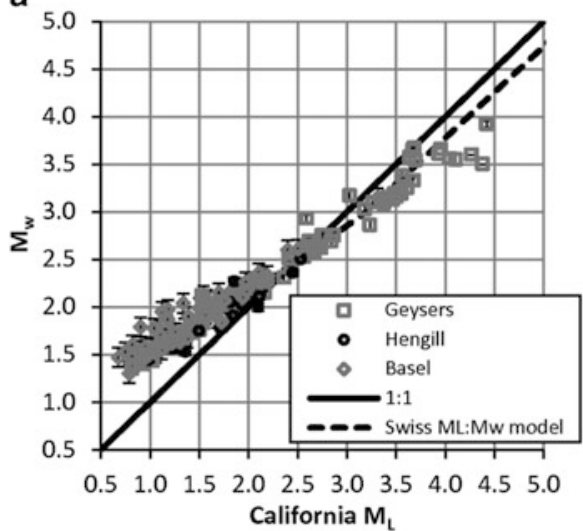

b

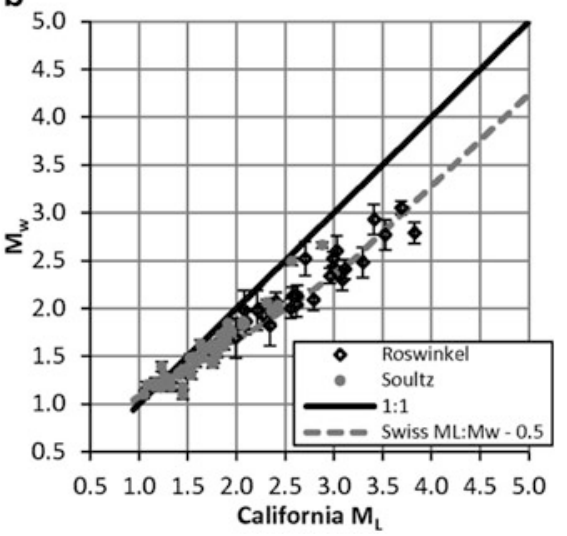

Fig. 18.4 Comparison of common $M_{L}$ scale versus inverted $M_{w}$ for all datasets in the study. (a) Geysers, Hengill and Basel events, along with the Swiss $\mathrm{M}_{\mathrm{L}}: \mathrm{M}_{\mathrm{w}}$ model of (Goertz-Allmann et al. 2011). (b) Roswinkel and Soultz events plotted along with the Swiss $M_{L}: M_{w}$ model offset by 0.5 units. From Edwards and Douglas (2014)

$M_{\text {equiv }}$ (Bommer et al. 2006) Edwards and Douglas (2014) found that the analysed datasets fell into two subsets offset by 0.5 magnitude units, with well-defined relation to $\mathrm{M}_{\mathrm{w}}$ (Fig. 18.4a, b). $\mathrm{M}_{\text {equiv }}$ was shown to correlate 1:1 with $\mathrm{M}_{\mathrm{L}}$, albeit with region-specific offsets. 


\subsection{Discussion}

From the analysis presented here it is clearly important for consistent and transparent magnitude determination at various stages of seismic hazard analysis. A key conclusion is that if one assumes that the moment magnitude $\mathrm{M}_{\mathrm{w}}$ follows the G-R relationship, then the $\mathrm{M}_{\mathrm{L}}$ scale does not. The most significant deviation is for $M_{L}>5$, where we begin to see the effect of magnitude scale saturation, which leads to locally increased b-values. The magnitude at which this saturation effect occurs depends on the stress-drop. Very low stress-drop events (e.g., $0.1 \mathrm{MPa}$ ) led to magnitude saturation effects impacting the b-value estimation at $\mathrm{M} \approx 4-5$. However, since this effect is most significant in the magnitude range where direct computation of $\mathrm{M}_{\mathrm{w}}$ is typically available, it is not an issue in PSHA. More importantly for induced seismicity is the fact that at lower magnitudes we noticed that the b-value is typically reduced (for all but the lowest stress-drop catalogue). This is related to the fact that for $\mathrm{M}_{\mathrm{w}} \approx 3-5, \mathrm{M}_{\mathrm{L}}$ values tend to be greater than $\mathrm{M}_{\mathrm{w}}$ for the simulated catalogues (and empirical catalogues), while at lower magnitudes, the difference reverses $\left(M_{w}\right.$ tends to be greater than $\left.M_{L}\right)$. Attenuation tends to systematically decrease the b-value computed with $\mathrm{M}_{\mathrm{L}}$ because it affects increasingly smaller events (with proportionally more high frequency energy) more strongly. For instance, attenuation can be considered as a low-pass filter: for large events with little high frequency energy (relative to the low-frequency energy), this filter has little effect, whereas for smaller events a significant portion of the energy is cut from the signal. Nevertheless, it is evident that these effects offset one another, or are minimised to a certain degree when choosing particular magnitude ranges (e.g., when using $3 \leq \mathrm{M}_{\mathrm{w}} \leq 5$, as often the case in hazard studies related to tectonic seismicity).

Routine computation of $\mathrm{M}_{\mathrm{L}}$ is often a requirement in order to have a complete data catalogue for computing the $\mathrm{G}-\mathrm{R}$ relation at small magnitudes. Best practice for recovering b-values should be to convert $\mathrm{M}_{\mathrm{L}}$ using a quadratic polynomial (Grünthal et al. 2009) or curvilinear function (Goertz-Allmann et al. 2011) (Fig. 18.5). The form of this polynomial will depend on:

(a) the local conditions - including source properties (e.g., stress drop or slip velocity), path attenuation ( $\mathrm{Q}$ and geometrical spreading) and site effects (amplification and attenuation) (Edwards et al. 2010);

(b) the form of the $\mathrm{M}_{\mathrm{L}}$ equation used (Edwards and Douglas 2014).

Since data $M_{w}-M_{L}$ pairs are rarely available down to small enough magnitudes; one option to consider is the creation of synthetic catalogues, as used in this chapter. Different source, path and site modelling terms can then also be used to cover the epistemic uncertainty of the $\mathrm{M}_{\mathrm{L}}$ to $\mathrm{M}_{\mathrm{w}}$ conversion.

Finally, even when we have a homogenous moment magnitude scale and consistent G-R source models, analysis by Douglas et al. (2013) highlighted 


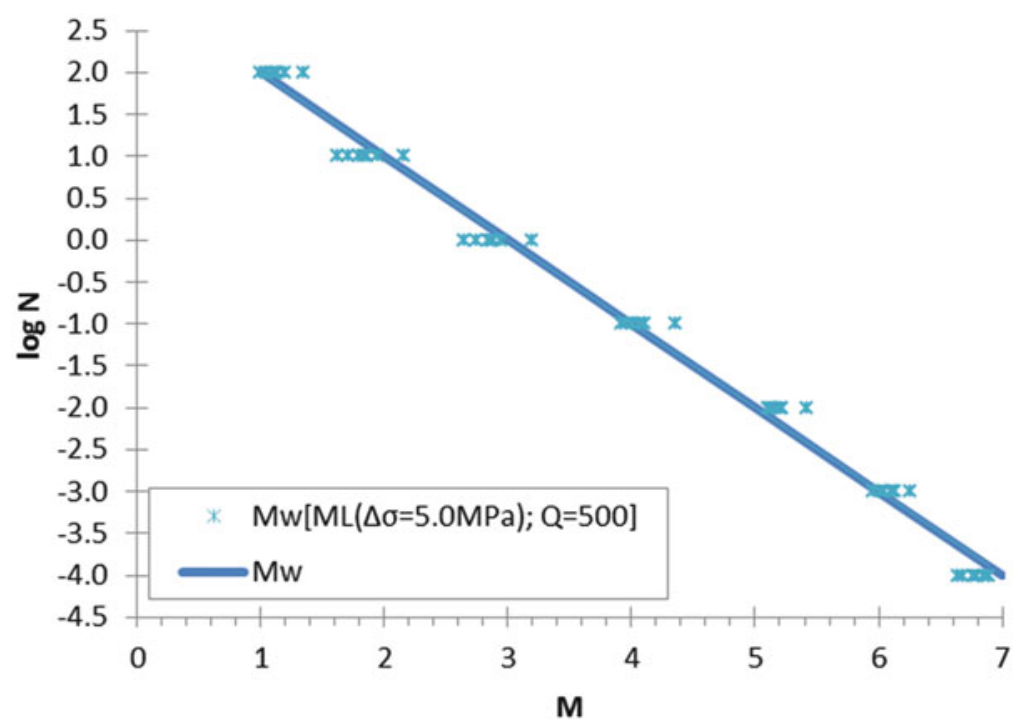

Fig. 18.5 G-R determined from $M_{L}$ converted to $M_{w}$ using a second order polynomial equation. Note that the $G-R$ fit to the $M_{w}\left(M_{L}\right)$ data points exactly coincides with the reference G-R for the $\mathrm{M}_{\mathrm{w}}$

considerable variation in source and path parameters (e.g., stress-drops, local attenuation) among different regions and sites. Both $\mathrm{M}_{\mathrm{L}}$ to $\mathrm{M}_{\mathrm{w}}$ conversions and ground motion prediction may therefore be region dependent. While the focus here has been on the computation of magnitude for defining G-R models, consistency should be ensured between the conversion used for $\mathrm{M}_{\mathrm{w}}\left(\mathrm{M}_{\mathrm{L}}\right)$ and the model terms used for ground motion prediction in PSHA (or deterministic/scenario based hazard). Clearly, when conducting seismic hazard assessment for a given geothermal project it is not known a priori which source, path and site terms (or equivalent GMPEs) are most applicable. However, Edwards and Douglas (2013) showed that as seismograms are recorded at a site, the applicability of particular models becomes quickly evident using either spectral or residual analysis approaches. It is therefore important to establish and maintain an optimised and effective monitoring network, with broad-band (and if possible, borehole) instrumentation. While region specific wave-propagation behaviour is initially difficult to define, it has the advantage that significantly lower values of uncertainty can be observed compared to previous studies combining small earthquakes from different regions.

Open Access This chapter is distributed under the terms of the Creative Commons Attribution Noncommercial License, which permits any noncommercial use, distribution, and reproduction in any medium, provided the original author(s) and source are credited. 


\section{References}

Aki K (1965) Maximum likelihood estimate of $\mathrm{b}$ in the formula $\log \mathrm{N}=\mathrm{a}-\mathrm{bM}$ and its confidence limits. Bull Earthquake Res Inst 43:237-239

Baer M, Deichmann N, Braunmiller J, Clinton J, Husen S, Fah D, Giardini D, Kastli P, Kradolfer U, Wienier S (2007) Earthquakes in Switzerland and surrounding regions during 2006. Swiss J Geosci 100:517-528. doi:10.1007/s00015-007-1242-0

Bender B (1983) Maximum-likelihood estimation of b-values for magnitude grouped data. Bull Seismol Soc Am 73:831-851

Bommer JJ, Oates S, Cepeda JM, Lindholm C, Bird J, Torres R, Marroquin G, Rivas J (2006) Control of hazard due to seismicity induced by a hot fractured rock geothermal project. Eng Geol 83:287-306. doi:10.1016/j.enggeo.2005.11.002

Boore DM (2003) Simulation of ground motion using the stochastic method. Pure Appl Geophys 160:635-676

Bormann P, Liu R, Xu Z, Ren K, Zhang L, Wendt S (2009) First application of the new IASPEI teleseismic magnitude standards to data of the china national seismographic network. Bull Seismol Soc Am 99:1868-1891. doi:10.1785/0120080010

Brune JN (1970) Tectonic stress and spectra of seismic shear waves from earthquakes. J Geophys Res 75:4997-5009

Brune JN (1971) Correction. J Geophys Res 76:5002

Cartwright DE, Longuet-Higgins MS (1956) The statistical distribution of the maxima of a random function. Proc Roy Soc Lond A Math Phys Sci 237:212-232

Choy GL, Boatwright JL (1995) Global patterns of radiated seismic energy and apparent stress. J Geophysical Res Solid Earth 100:18205-18228

Cornell CA (1968) Engineering seismic risk analysis. Bull Seismol Soc Am 58:1583-\&

Cornell CA, Vanmarcke EH (1969) The major influences on seismic risk. In: Proceedings of the fourth world conference on earthquake engineering, vol 1, Chile, pp 69-83

Deichmann N, Giardini D (2009) Earthquakes induced by the stimulation of an enhanced geothermal system below Basel (Switzerland). Seismol Res Lett 80:784-798. doi:10.1785/gssrl. 80.5.784

Douglas J, Edwards B, Convertito V, Sharma N, Tramelli A, Kraaijpoel D, Cabrera BM, Maercklin N, Troise C (2013) Predicting ground motion from induced earthquakes in geothermal areas. Bull Seismol Soc Am 103:1875-1897. doi:10.1785/0120120197

Edwards B, Douglas J (2013) Selecting ground-motion models developed for induced seismicity in geothermal areas. Geophys J Int 195:1314-1322. doi:10.1093/gji/ggt310

Edwards B, Douglas J (2014) Magnitude scaling of induced earthquakes. Geothermics 52:132-139. doi: http://dx.doi.org/10.1016/j.geothermics.2013.09.012

Edwards B, Allmann B, Fäh D, Clinton J (2010) Automatic computation of moment magnitudes for small earthquakes and the scaling of local to moment magnitude. Geophys $\mathrm{J}$ Int 183:407-420. doi:10.1111/j.1365-246X.2010.04743.x

Edwards B, Kraft T, Cauzzi C, Kästli P, Wiemer S (2015) Seismic monitoring and analysis of deep geothermal projects in St Gallen and Basel, Switzerland. Geophys J Int 201:1020-1037. doi:10.1093/gji/ggv059

Ellsworth WL (2013) Injection-induced earthquakes. Science 341:142-+. doi:10.1126/Science. 1225942

Eshelby JD (1957) The determination of the elastic field of an ellipsoidal inclusion, and related problems. Proc Roy Soc Lond A Math Phys Sci 241:376-396

Fäh D, Giardini D, Kästli P, Deichmann N, Gisler M, Schwarz-Zanetti G, Alvarez-Rubio S, Sellami S, Edwards B, Allmann B (2011) Ecos-09 earthquake catalogue of Switzerland release 2011 report and database. Public catalogue, 17. 4. 2011. Swiss seismological service eth Zurich, p 42

Giardini D (2009) Geothermal quake risks must be faced. Nature 462:848-849. doi:10.1038/ $462848 \mathrm{a}$ 
Goertz-Allmann BP, Edwards B, Bethmann F, Deichmann N, Clinton J, Fäh D, Giardini D (2011) A new empirical magnitude scaling relation for Switzerland. Bull Seismol Soc Am 101:3088-3095. doi:10.1785/0120100291

Grünthal G, Wahlstrom R, Stromeyer D (2009) The unified catalogue of earthquakes in central, northern, and northwestern Europe (CENEC)-updated and expanded to the last millennium. J Seismol 13:517-541. doi:10.1007/s10950-008-9144-9

Gutenberg B, Richter CF (1944) Frequency of earthquakes in California. Bull Seismol Soc Am $34: 185-188$

Hanks TC, Boore DM (1984) Moment-magnitude relations in theory and practice. J Geophys Res 89:6229-6235. doi:10.1029/Jb089ib07p06229

Hanks TC, Kanamori H (1979) Moment magnitude scale. J Geophys Res 84:2348-2350

Herrmann RB (1985) An extension of random vibration theory estimates of strong ground motion to large distances. Bull Seismol Soc Am 75:1447-1453

Kijko A (1985) A modified form of the Gutenberg-Richter magnitude frequency relation maximum-likelihood estimation of its parameters. Bull Seismol Soc Am 75:319-322

Knopoff L (1964) Q. Rev Geophys 2:625-660

Lee WHK, Brillinger DR (1979) Chinese earthquake history - attempt to model an incomplete data set by point process analysis. Pure Appl Geophys 117:1229-1257. doi:10.1007/ Bf00876217

Liu L, Pezeshk S (1999) An improvement on the estimation of pseudoresponse spectral velocity using RVT method. Bull Seismol Soc Am 89:1384-1389

Richter CF (1935) An instrumental earthquake magnitude scale. Bull Seismol Soc Am 25:1-32

Schorlemmer D, Wiemer S, Wyss M (2005) Variations in earthquake-size distribution across different stress regimes. Nature 437:539-542. doi:10.1038/Nature04094

Smith SW (1976) Determination of maximum earthquake magnitude. Geophysical Research Letters 3:351-354. doi:10.1029/G1003i006p00351

Spada M, Tormann T, Wiemer S, Enescu B (2013) Generic dependence of the frequency-size distribution of earthquakes on depth and its relation to the strength profile of the crust. Geophys Res Lett 40:709-714. doi:10.1029/2012g1054198

Stork AL, Verdon JP, Kendall J-M (2014) The robustness of seismic moment and magnitudes estimated using spectral analysis. Geophys Prospect 62:862-878. doi:10.1111/1365-2478. 12134

Tinti S, Mulargia F (1985) Effects of magnitude uncertainties on estimating the parameters in the Gutenberg-Richter frequency-magnitude law. Bull Seismol Soc Am 75:1681-1697

Utsu T (1965) A method for determining the value of $b$ in a formula $\log n=a-b m$ showing the magnitude-frequency relation for earthquakes. Geophys Bull Hokkaido Univ 13:103

Weichert DH (1980) Estimation of the earthquake recurrence parameters for unequal observation periods for different magnitudes. Bull Seismol Soc Am 70:1337-1346

Wiemer S, Wyss M (1997) Mapping the frequency-magnitude distribution in asperities: An improved technique to calculate recurrence times? J Geophys Res Solid Earth 102:15115-15128. doi:10.1029/97jb00726

Wiemer S, Wyss M (2002) Mapping spatial variability of the frequency-magnitude distribution of earthquakes. Adv Geophys 45(45):259-302 